\title{
NUMERICAL CALCULATION OF DYNAMIC STIFFNESS AND DAMPING COEFFICIENTS OF OIL LUBRICATION FILM IN INTERNAL GEAR MOTORS AND PUMPS
}

\author{
Pham Trong Hoa, Nguyen Manh Hung \\ University of Transport and Communications (UTC), No.3, Cau Giay str., Lang Thuong ward, Dong Da district, \\ Ha Noi, Vietnam.
}

\begin{abstract}
Oil lubrication film plays an important role in analysis of dynamic behavior of the internal gear motors and pumps. During operation, the oil film is considered as the spring and damping system. Therefore, calculation of the dynamic stiffness and damping coefficients is necessary to build the mathematical model for studying of dynamic problem. In order to calculate these coefficients, the dynamic pressure and perturbing pressure distribution must be determined firstly. In this paper, the infinitesimal perturbation method (IFP) is used to calculate the dynamic pressure distribution. Based on that the dynamic stiffness and damping coefficients can be computed. The calculation results point out that the dynamic stiffness and damping coefficients are much dependent on the eccentricity ratio.
\end{abstract}

Keywords: Internal gear motors and pumps, dynamic pressure, stiffness and damping coefficients.

\section{INTRODUCTION}

The oil lubrication film is very important for rotating machines [1]. Dynamic behavior of the internal gear motor and pump is much dependent on the characteristics of the oil film between the outer ring gear and inner housing. A mathematical model for studying of dynamic behavior of internal gear motor and pump has not been introduced so far [2]. One reason is the difficulty of determination of dynamic stiffness and damping coefficients. Pham in study $[3,4]$ analyzed the dynamic problem of internal gear motor and pump by using the mobility method with some modifications. The stability problem of internal gear motors and pumps has been observed and introduced in study [5] through experimental results.

Unlikely to other rotating machines, for internal gear motor and pump, the oil lubrication is also the working oil. Among those parameters of oil film, the stiffness and damping coefficients are the most important. In the study [6] Pham et al., calculated the static stiffness and damping coefficients and analyze the effect of some geometric parameters on static stiffness and damping coefficients. These coefficients are found by linearizing the ring gear force at the steady state condition. In order to calculate the dynamic stiffness and damping factors, the dynamic pressure distribution must be determined. Lots of studies relating to the internal gear and pump so far, however, the study of dynamic stiffness and damping coefficients have been not performed. The calculation of the dynamic oil film stiffness and damping factors will be the fundamental issues to study dynamic problem of the internal gear motor and pump.

\section{MATHEMATICAL MODEL}

The cross section of the internal gear motor and pump is described in Figure 1. A motor/pump unit contains of three main elements, e.g., driving gear, ring gear and housing. It is widely used due to its simplification and economy. To avoid the metal - to - metal contact between the outer ring gear and inner housing, the oil thin film is required. Unlikely to other rotating machines, the oil lubrication of the internal gear motor and pump is also the working oil. During operation, the oil film is considered as the spring and damper system as shown in Figure 2. It contains both the direct coefficients $\left(\mathrm{k}_{\mathrm{xx}}, \mathrm{k}_{\mathrm{yy}}\right.$ and $\left.\mathrm{b}_{\mathrm{xx}}, \mathrm{b}_{\mathrm{yy}}\right)$ and the cross-coupling coefficients $\left(\mathrm{k}_{\mathrm{xy}}, \mathrm{k}_{\mathrm{yx}}\right.$ and $\left.b_{x y}, b_{y x}\right)$. These parameters are functions of the eccentricity ratio $\varepsilon(\mathrm{e} / \mathrm{c})$. The nominal gap between the outer ring gear and inner housing is called the radial clearance (c). e is the eccentricity of the ring gear. It is the distance from the ring 
gear center to the housing center. The eccentricity is dependent on the working conditions. The oil lubrication film over the circumferential direction is not evenly as shown in Figure 3. The oil film thickness is a function of eccentricity (e) and position angle $(\theta)$ of the ring gear center which is presented in equation (1)

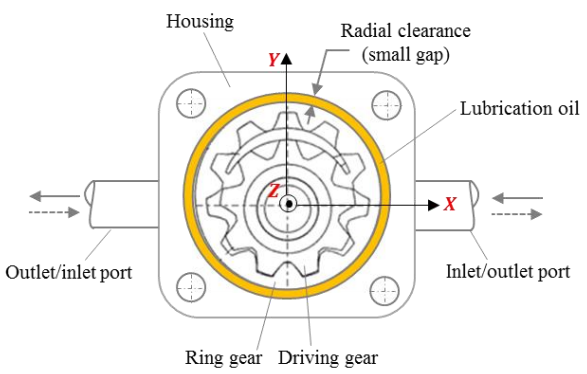

Figure 1: Internal gear motor and pump

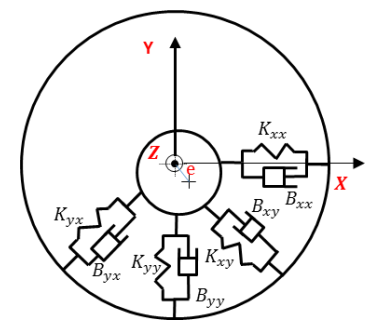

Figure 2: Mass-Spring-Damping model

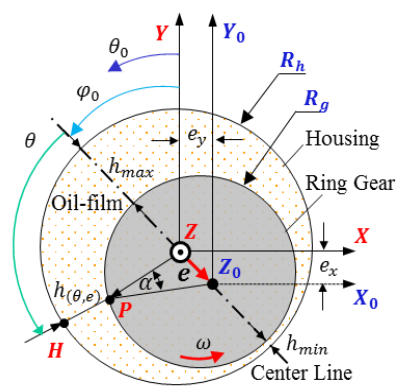

Figure 3: Oil film thickness

$$
\mathrm{h}_{(\theta, \mathrm{e})}=\mathrm{c}(1+\varepsilon \cos \theta)
$$

\subsection{The non-linear model}

Oil film force is dependent on the ring gear position and velocities, i.e.,

$$
\left\{\begin{array}{l}
F_{x}=F_{x}(x, y, \dot{x}, \dot{y}) \\
F_{y}=F_{y}(x, y, \dot{x}, \dot{y})
\end{array}\right.
$$

The oil film force can be calculated by integrating the oil film pressure in both horizontal and vertical directions [7]:

$$
\left[\begin{array}{l}
\mathrm{F}_{\mathrm{x}} \\
\mathrm{F}_{\mathrm{y}}
\end{array}\right]=-\int_{\theta_{1}}^{\theta_{2}} \int_{0}^{\mathrm{L}} \mathrm{p}\left[\begin{array}{c}
\sin \theta \\
\cos \theta
\end{array}\right](\operatorname{Rd} \theta) \mathrm{dz}
$$

The oil film force is determined as,

$$
\left\{\begin{array}{l}
F_{x}=K_{x x} x+K_{x y} y+B_{x x} \dot{x}+B_{x y} \dot{y} \\
F_{y}=K_{y x} x+K_{y y} y+B_{y x} \dot{x}+B_{y y} \dot{y}
\end{array}\right.
$$

In which, the stiffness and damping coefficients are defined as follows,

$$
\left\{\begin{array}{l}
\mathrm{K}_{\mathrm{xx}}=\frac{\partial \mathrm{F}_{\mathrm{x}}}{\partial \mathrm{x}}, \mathrm{K}_{\mathrm{xy}}=\frac{\partial \mathrm{F}_{\mathrm{x}}}{\partial \mathrm{y}}, \mathrm{K}_{\mathrm{yx}}=\frac{\partial \mathrm{F}_{\mathrm{y}}}{\partial \mathrm{x}}, \mathrm{K}_{\mathrm{yy}}=\frac{\partial \mathrm{F}_{\mathrm{y}}}{\partial \mathrm{y}} \\
\mathrm{B}_{\mathrm{xx}}=\frac{\partial \mathrm{F}_{\mathrm{x}}}{\partial \dot{\mathrm{x}}}, \mathrm{B}_{\mathrm{xy}}=\frac{\partial \mathrm{F}_{\mathrm{x}}}{\partial \dot{\mathrm{y}}}, \mathrm{B}_{\mathrm{yx}}=\frac{\partial \mathrm{F}_{\mathrm{y}}}{\partial \dot{\mathrm{x}}}, \mathrm{B}_{\mathrm{yy}}=\frac{\partial \mathrm{F}_{\mathrm{y}}}{\partial \dot{\mathrm{y}}}
\end{array}\right.
$$

These coefficients are called as nonlinear or dynamic oil-film stiffness and damping. Calculation of these coefficients is important in the dynamic analysis for internal gear motor and pump. Normally there are two theoretical model to calculate these linear factors, i.e., Infinitesimal perturbation method (IFP) and finite perturbation method (FP). In this study, the infinitesimal perturbation method (IFP) is used. The infinitesimal perturbation method uses the partial derivatives of the ring gear with respect to the displacements and velocities to calculate the force factors [8].

$$
\left[\begin{array}{l}
\mathrm{K}_{\mathrm{xx}} \\
\mathrm{K}_{\mathrm{xy}} \\
\mathrm{K}_{\mathrm{yx}} \\
\mathrm{K}_{\mathrm{yy}} \\
\mathrm{B}_{\mathrm{xx}} \\
\mathrm{B}_{\mathrm{yx}} \\
\mathrm{B}_{\mathrm{yy}}
\end{array}\right]=\left[\begin{array}{l}
\frac{\partial \mathrm{F}_{\mathrm{x}}}{\partial \mathrm{x}} \\
\frac{\partial \mathrm{F}_{\mathrm{x}}}{\partial \mathrm{y}} \\
\frac{\partial \mathrm{F}_{\mathrm{y}}}{\partial \mathrm{x}} \\
\frac{\partial \mathrm{F}_{\mathrm{y}}}{\partial \mathrm{y}} \\
\frac{\partial \mathrm{F}_{\mathrm{x}}}{\partial \dot{\mathrm{x}}} \\
\frac{\partial \mathrm{F}_{\mathrm{x}}}{\partial \dot{\mathrm{y}}} \\
\frac{\partial \mathrm{F}_{\mathrm{y}}}{\partial \dot{\mathrm{x}}} \\
\frac{\partial \mathrm{F}_{\mathrm{y}}}{\partial \dot{y}}
\end{array}\right]=-\mathrm{R}_{\theta_{1}}^{\theta_{2}} \int_{0}^{\mathrm{L}}\left[\begin{array}{c}
\mathrm{p}_{\mathrm{x}} \sin \theta \\
\mathrm{p}_{\mathrm{y}} \sin \theta \\
\mathrm{p}_{\mathrm{x}} \cos \theta \\
\mathrm{p}_{\mathrm{y}} \cos \theta \\
\mathrm{p}_{\dot{\mathrm{x}}} \sin \theta \\
\mathrm{p}_{\dot{\mathrm{y}}} \sin \theta \\
\mathrm{p}_{\dot{\mathrm{x}}} \cos \theta \\
\mathrm{p}_{\dot{\mathrm{y}}} \cos \theta
\end{array}\right] \mathrm{d} \theta \mathrm{dz}
$$


These perturbing pressure component are computed as follows

$$
\left\{\begin{array}{l}
p_{o}=(p)_{o} \\
p_{x}=\left(\frac{\partial p}{\partial x}\right)_{0} \\
p_{y}=\left(\frac{\partial p}{\partial y}\right)_{0} \\
p_{\dot{x}}=\left(\frac{\partial p}{\partial \dot{x}}\right)_{0} \\
p_{\dot{y}}=\left(\frac{\partial p}{\partial \dot{y}}\right)_{0}
\end{array}\right.
$$

These pressure components are obtained by solving of the Reynold's equations:

$$
\begin{gathered}
\frac{\partial}{\partial \theta}\left(h^{3} \frac{\partial}{\partial \theta}\right)+\frac{\partial}{\partial z}\left(h^{3} \frac{\partial}{\partial z}\right)\left(\begin{array}{l}
p_{0} \\
p_{x} \\
p_{y} \\
p_{\dot{x}} \\
p_{\dot{y}}
\end{array}\right) \\
=\left(\begin{array}{c}
\frac{\partial h}{\partial \theta} \\
\cos \theta-3 \frac{\partial}{\partial \theta}\left(h^{2} \sin \theta \frac{\partial p_{0}}{\partial \theta}\right)-3 \frac{\partial}{\partial z}\left(h^{2} \sin \theta \frac{\partial p_{0}}{\partial z}\right) \\
\sin \theta-3 \frac{\partial}{\partial \theta}\left(h^{2} \cos \theta \frac{\partial p_{0}}{\partial \theta}\right)-3 \frac{\partial}{\partial z}\left(h^{2} \cos \theta \frac{\partial p_{0}}{\partial z}\right) \\
2 \sin \theta \\
2 \cos \theta
\end{array}\right)
\end{gathered}
$$

By solving the Reynolds equation for each pressure component, the dynamic forces components are defined. From equation (8), the static pressure po and four perturbing pressure $\mathrm{px}$, py, $p_{-} x^{*}$ and $p \_y^{\prime}$ can be solved. Based on that, eight stiffness and damping coefficients can be calculated by integrating these perturbing pressure as in (6).

\section{Definition of the solution domain and boundary conditions:}

To increase the accuracy, perturbation is normally performed in both positive and negative directions. After governing the controlling equation for the pressure distribution Eq. (8), the boundary conditions for calculation of the pressure distribution must be defined. For the computation of the pressure distribution from the Reynolds equation, the pressure field at the edge is assumed to equal zero. For the $\mathrm{m}^{*} \mathrm{n}$ grid points of the pressure, $m * n$ equations are established. However, the pressure at all the edge points $(\mathrm{m}+1)^{*}(\mathrm{n}+1)$ is equal to zero. Therefore it is needed to write the pressure equation for the other points inside the grid net. Numerical procedure is presented in Figure 4.

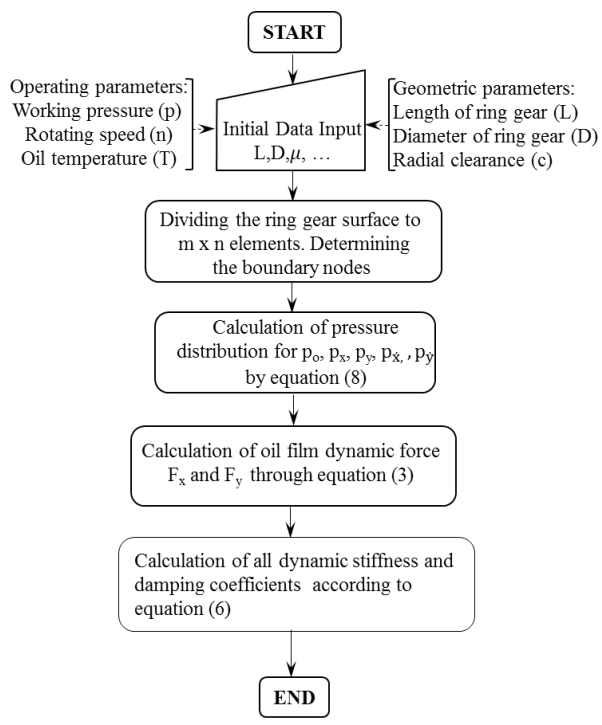

Figure 4: Calculation procedure

Table 1: Geometrics parameters of internal gear motor and pump

\begin{tabular}{lllll}
\hline Parameter & Symbol & Value & Unit \\
\hline $\begin{array}{l}\text { Diameter of } \\
\text { gear }\end{array}$ & & $\mathrm{D}$ & 0.11 & $\mathrm{~m}$ \\
\hline $\begin{array}{l}\text { Length of ring } \\
\text { gear }\end{array}$ & $\mathrm{L}$ & 0.017 & $\mathrm{~m}$ \\
\hline Dynamic viscosity & $\begin{array}{l}\mu \\
\mathrm{HLP} 46)\end{array}$ & (Oil & 0.04 & $\mathrm{~Pa} . \mathrm{s}$ \\
\hline Rotating speed & $\mathrm{n}$ & 2000 & $\mathrm{rpm}$ \\
\hline Working pressure & $\mathrm{\Delta} \mathrm{p}$ & 200 & $\mathrm{bar}$ \\
\hline Radial clearance & $\mathrm{c}$ & $50.10^{-6}$ & $\mathrm{~m}$ \\
\hline Temperature & $\mathrm{T}$ & $40^{\circ}$ & $\mathrm{C}$ \\
\hline
\end{tabular}




\section{RESULTS AND DISCUSSION}

\subsection{Distribution of pressure components}

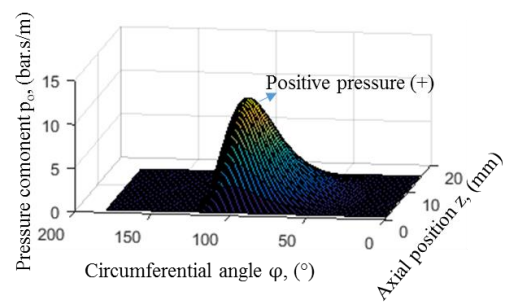

Figure 5: Hydrodynamic pressure distribution $p_{0}$

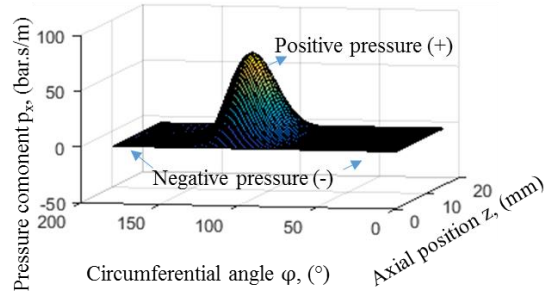

Figure 6: Distribution of pressure component $\mathrm{p}_{\mathrm{x}}$

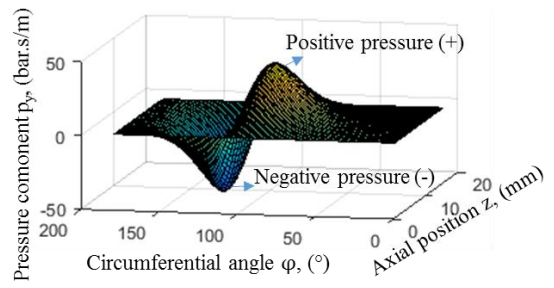

Figure 7: Distribution of pressure component $p_{y}$

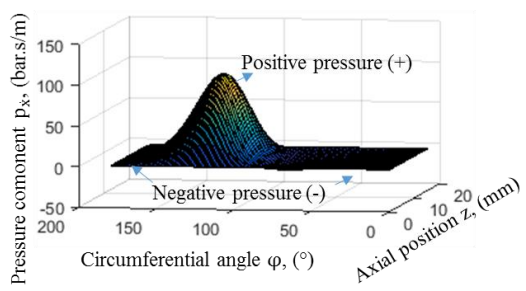

Figure 8: Distribution of pressure component $\mathrm{p}_{\mathrm{x}}$

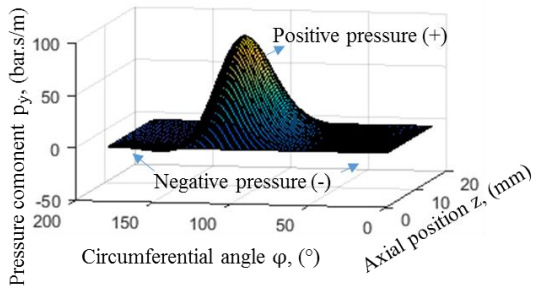

Figure 9: Distribution of pressure component $p_{y}$

Figure 5 shows 2D hydrodynamic pressure distribution at the eccentricity ratio of 0.5 . The pressure mountain distributes from $30^{\circ}$ to $125^{\circ}$ in circumferential direction. The maximum value of hydrodynamic pressure stays around $110^{\circ}$. The perturbing pressure component are presented from Figure 6 to Figure 9, respectively. One can see that for all perturbing pressure exists the both types of pressure, e.g., positive and negative pressure elements. The area of negative and positive pressure vary for different perturbing pressure component. The existence of the negative pressure component represents for the changing of velocities and acceleration of ring gear. It reduces the values of dynamic stiffness and damping coefficients. The dynamic stiffness coefficients are calculated through the perturbing pressure px and py. Meanwhile, the dynamic damping coefficients are dependent on the perturbing pressure component $\mathrm{p}_{\mathrm{x}}$ and $\mathrm{p}_{\mathrm{y}}$.

\subsection{Analysis of effect of eccentricity on pressure component}

As mentioned above, the dynamic pressure is a function of the eccentricity. The effect of eccentricity on the hydrodynamic pressure distribution is shown in Figure 10. It is obviously to see that for low values of eccentricity ratio, the area of hydrodynamic pressure distribution is larger than that of high values of eccentricity ratio. However, the maximum hydrodynamic pressure at the high values of eccentricity is much larger than that of low values, for example the maximum pressure at eccentricity ratio of 0.2 is about 2.1 bar whereas the maximum pressure at eccentricity ratio of 0.8 reaches up to 105 bar. 


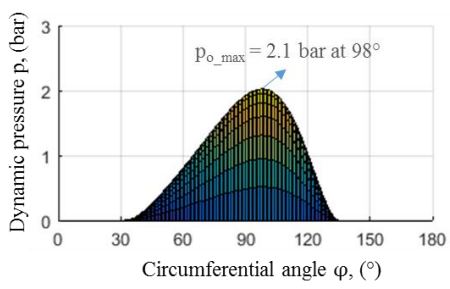

Figure a: Eccentricity ratio of 0.2

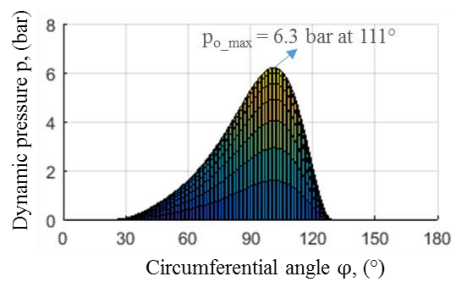

Figure b: Eccentricity ratio of 0.4

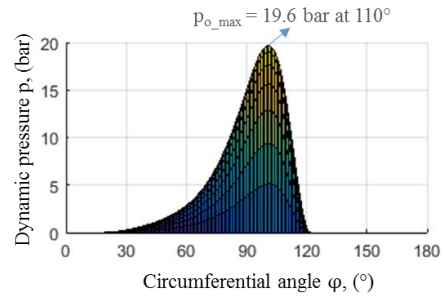

Figure c: Eccentricity ratio of 0.6

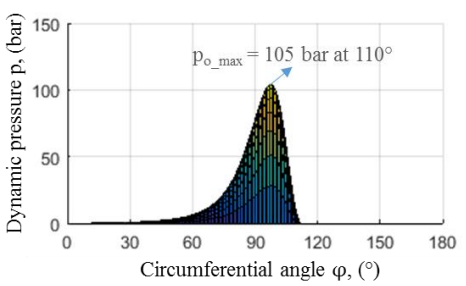

Figure d: Eccentricity ratio of 0.8

Figure 10: Effect of eccentricity on the hydrodynamic pressure distribution $p_{o}$ at middle axial plane.

The effect of eccentricity on the perturbing pressure distribution $p_{x}$ is shown in Figure 11 . One can see that the perturbing pressure $p_{x}$ changes according to the change of the eccentricity ratio. It always exists both negative and positive pressure elements. The area of positive pressure is reduced according to the increase of the eccentricity ratio, however, the maximum value of pressure is greatly increased, e.g., $1130 \mathrm{bar} / \mathrm{m}$ at $98^{\circ}$ for eccentricity ratio value of 0.8 compared to $16.2 \mathrm{bar} / \mathrm{m}$ at $112^{\circ}$ for eccentricity ratio value of 0.2 .

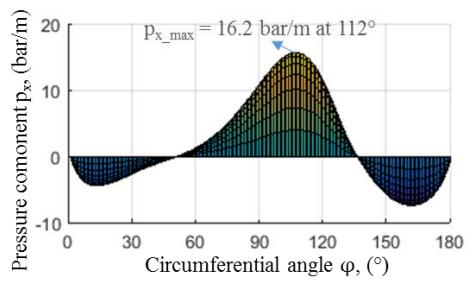

Figure a: Eccentricity ratio of 0.2

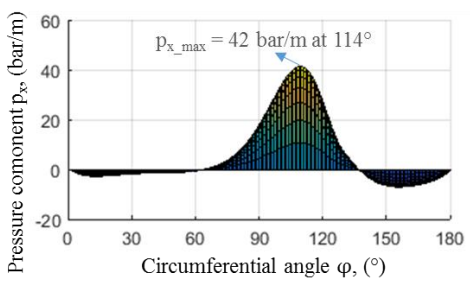

Figure b: Eccentricity ratio of 0.4

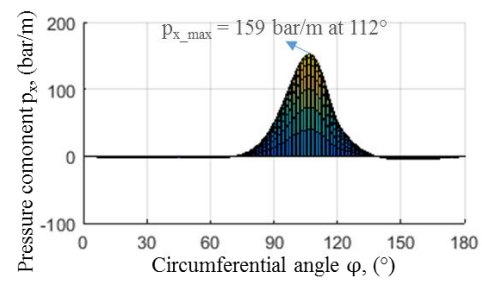

Figure c: Eccentricity ratio of 0.6

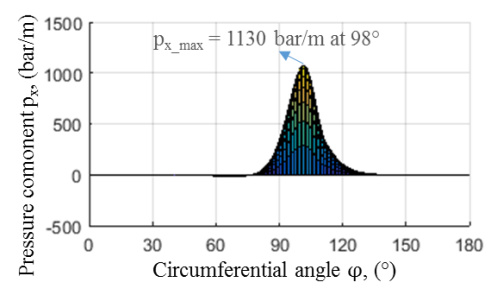

Figure d: Eccentricity ratio of 0.8

Figure 11: Effect of eccentricity on the 2D perturbing pressure distribution $\mathrm{p}_{\mathrm{x}}$ at middle axial plane.

The effect of eccentricity on the perturbing pressure distribution $p_{y}$ is shown in Figure 12 . The pressure distribution is divided into two areas, e.g., the left area is the positive pressure and the negative pressure places at the right side. 
As the increase of eccentricity ratio, the changing of both areas is not much, however, the maximum values and the position of the positive pressure is greatly changed, e.g., 8.3 bar.s $/ \mathrm{m}$ at $78^{\circ}$ for the eccentricity ratio value of 0.2 compared to 1190 bar.s $/ \mathrm{m}$ at $96^{\circ}$ for the eccentricity ratio value of 0.8 .

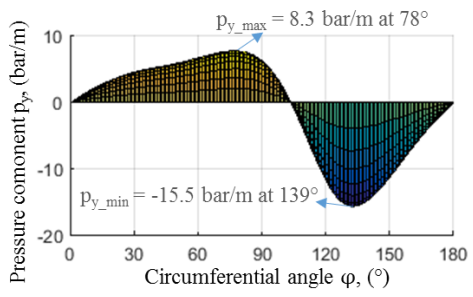

Figure a: Eccentricity ratio of 0.2

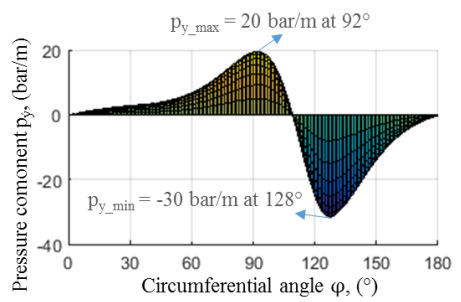

Figure b: Eccentricity ratio of 0.4

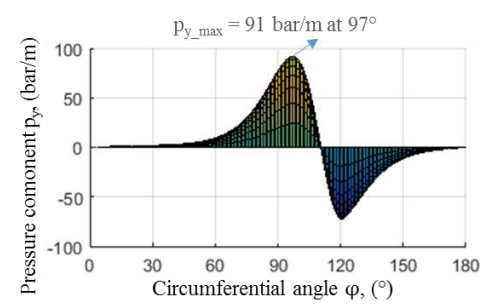

Figure c: Eccentricity ratio of 0.6

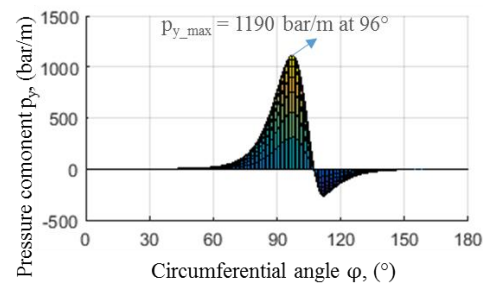

Figure d: Eccentricity ratio of 0.8

Figure 12: Effect of eccentricity on the 2D perturbing pressure distribution $p_{y}$ at middle axial plane.

The effect of eccentricity on the perturbing pressure distribution $p_{x}$ is shown in Figure 13.
The pressure distribution is divided into two areas, e.g., the left area is the negative pressure and the positive pressure places at the right side. The area of positive and negative pressure is slightly changed regarding to the change of the eccentricity ratio. However, the maximum values as well as the position of the positive pressure are much dependent on eccentricity ratio, e.g., 34 bar.s $/ \mathrm{m}$ at $132^{\circ}$ for the eccentricity ratio of 0.2 compared to 680 bar.s $/ \mathrm{m}$ at $105^{\circ}$ for the eccentricity ratio of 0.8 .

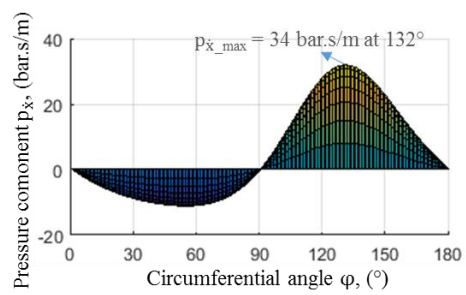

Figure a: Eccentricity ratio of 0.2

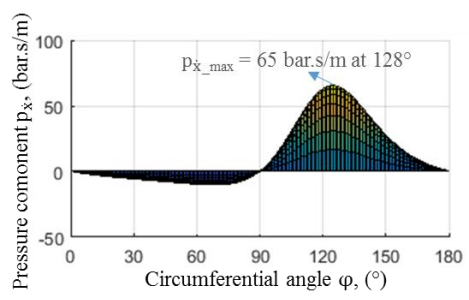

Figure b: Eccentricity ratio of 0.4

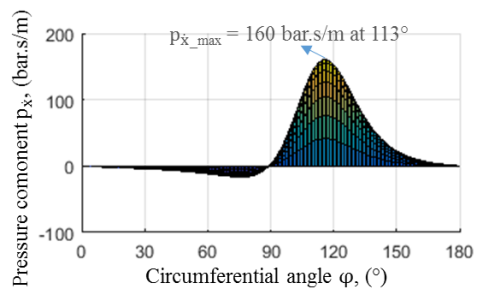

Figure c: Eccentricity ratio of 0.6 


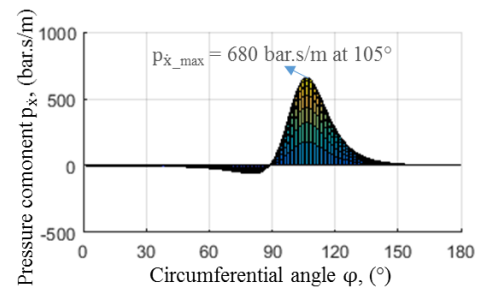

Figure d: Eccentricity ratio of 0.8

Figure 13: Effect of eccentricity on the 2D perturbing pressure distribution $\mathrm{p} \__{-} \cdot$ at middle axial plane.

Figure 14 shows the effect of eccentricity ratio on the perturbing pressure component $\mathrm{p}_{\mathrm{y}}$.

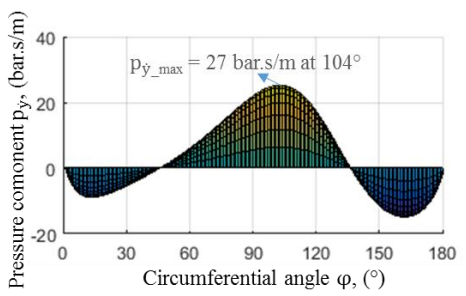

Figure a: Eccentricity ratio of 0.2

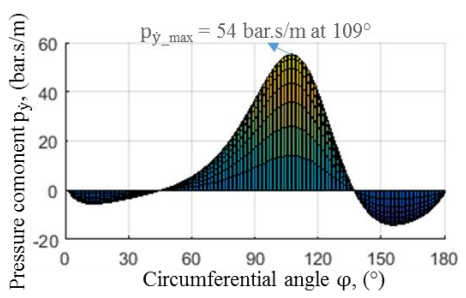

Figure b: Eccentricity ratio of 0.4

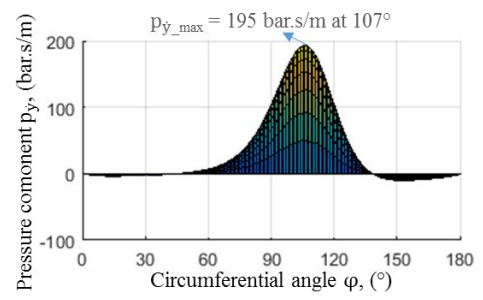

Figure c: Eccentricity ratio of 0.6

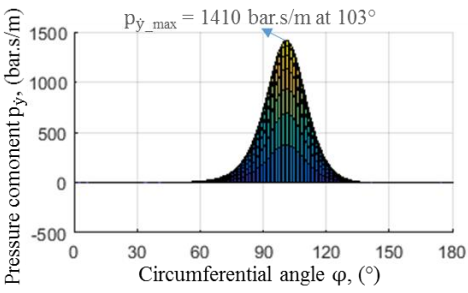

Figure d: Eccentricity ratio of 0.8

Figure 14: Effect of eccentricity on the 2D perturbing pressure distribution $\mathrm{p} \_\mathrm{y}^{\cdot}$ at middle axial plane.

\subsection{Analysis of effect of eccentricity on dynamic force of oil film}

The oil film produces the internal force or oil film force which against with the external force acting on the ring gear. In this study, the external or apply force is considered as a vertical force. The oil film force is dependent on the hydrodynamic pressure distribution and the eccentricity of the ring gear center. The oil film force contains two elements, i.e., the horizontal and vertical oil film force which are presented in Figure 15 and Figure 16, respectively. The vertical oil film force increases with the increase of the eccentricity ratio. However, the changing of horizontal oil film force is nonlinear. The value of vertical force is much larger than the horizontal force. This means that the capacity of the oil film is mostly decided by the vertical force component. The details of calculation are presented in Table 2.

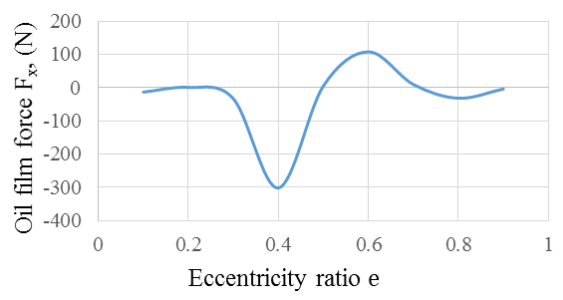

Figure 15: Effect of eccentricity on horizontal force $F_{x}$ of oil film. 


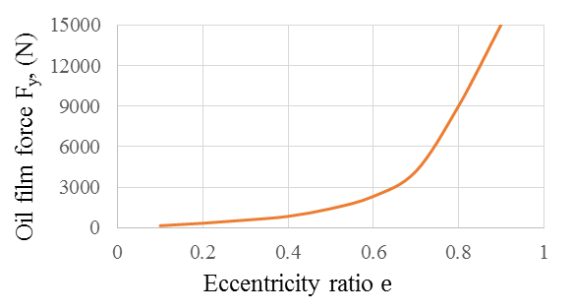

Figure 16: Effect of eccentricity on dynamic vertical force $\mathrm{F}_{\mathrm{y}}$ of oil film.

Table 2: Dynamic oil film force, $x 102 N$

\begin{tabular}{llll}
\hline $\mathrm{e}$ & $\mathrm{F}_{\mathrm{x}}$ & $\mathrm{F}_{\mathrm{y}}$ & $\mathrm{F}$ \\
\hline 0.1 & -0.013 .6 & 1.60 & 1.60 \\
\hline 0.2 & 0.0065 & 3.43 & 3.43 \\
\hline 0.3 & -0.33 & 5.75 & 5.76 \\
\hline 0.4 & -3.02 & 8.54 & 9.06 \\
\hline 0.5 & 0.0049 & 142.12 & 142.12 \\
\hline 0.6 & 1.07 & 232.78 & 232.78 \\
\hline 0.7 & 9.50 & 418.76 & 418.87 \\
\hline 0.8 & -0.32 & 901.63 & 901.63 \\
\hline 0.9 & -0.04 & 1504.4 & 1504.40 \\
\hline
\end{tabular}

\subsection{Analysis of effect of geometric parameters on dynamic stiffness and damping coefficients}

The direct and cross-coupling coefficients of the dynamic stiffness of oil lubrication film as functions of eccentricity ratio are presented in Figure 17. It shows that the dynamic oil film stiffness changes according to the change of the eccentricity ratio. These parameters are also called as dynamic oil-film force coefficients of the ring gear. Each dynamic stiffness coefficient have a wide range of values, dependent on the value of eccentricity ratio. For large value of eccentricity, these dynamic stiffness coefficients has large value, and vice versa. One can see from Figure 17 that when the eccentricity ratio is larger than 0.7, two dynamic stiffness coefficients $\mathrm{K}_{\mathrm{yy}}$ and $\mathrm{K}_{\mathrm{yx}}$ reach to much larger values. Similarity, the direct and cross-coupling coefficients of the linearized oil film damping as functions of eccentricity ratio are also presented in Figure 18. Each dynamic damping coefficients have a wide range of values, dependent on the value of eccentricity ratio. For large values of eccentricity, these dynamic damping coefficients have large values, and vice versa. It is obviously to see from Figure 18 that when the eccentricity ratio is larger than 0.7 , the dynamic damping factor $\mathrm{B}_{\mathrm{yy}}$ reaches to large value. The high values of stiffness coefficient component $\mathrm{K}_{\mathrm{yy}}$ and damping coefficient component $\mathrm{B}_{\mathrm{yy}}$ in the vertical direction will be better for stability of the ring gear at high value of eccentricity.

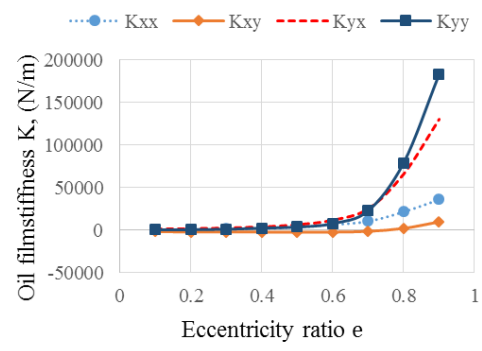

Figure 17: Dynamic stiffness coefficients as a function of eccentricity ratio.

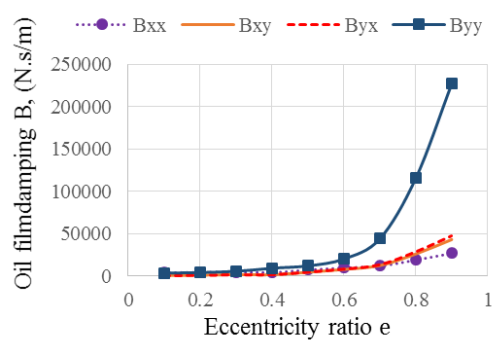

Figure 18: Dynamic damping coefficients as a function of eccentricity ratio.

The details of dynamic stiffness and damping coefficients are presented in Table 3 and Table 4, respectively.

Table 3: Dynamic stiffness coefficient, $\mathrm{N} / \mathrm{m}$

\begin{tabular}{|c|c|c|c|c|c|c|c|c|c|}
\hline $\mathrm{e}$ & 0.1 & 0.2 & 0.3 & 0.4 & 0.5 & 0.6 & 0.7 & 0.8 & 0.9 \\
\hline & $\mathrm{x} 10^{3}$ & & & & $\times 10^{4}$ & & & $\mathrm{x} 10^{5}$ & \\
\hline $\mathrm{Kxx}$ & 0.5 & 0.93 & 1.5 & 1.8 & 0.4 & 0.7 & 1.1 & 0.22 & 0.4 \\
\hline Kxy & -2 & -2.2 & - & $\overline{2}-4$ & -0.3 & $\begin{array}{l}- \\
0.2\end{array}$ & $\begin{array}{l}- \\
0.1\end{array}$ & 0.02 & 0.1 \\
\hline Kyx & 1.8 & 2.1 & 2.9 & 4.3 & 0.7 & 1.2 & 2.5 & 0.67 & 1.3 \\
\hline Kyy & 0.2 & 0.4 & 0.9 & 2.3 & 0.35 & 0.8 & 2.3 & 0.79 & 1.8 \\
\hline
\end{tabular}

Table 4: Dynamic damping coefficient, N.s/m

\begin{tabular}{|c|c|c|c|c|c|c|c|c|c|}
\hline $\mathrm{e}$ & 0.1 & 0.2 & 0.3 & 0.4 & 0.5 & 0.6 & 0.7 & 0.8 & 0.9 \\
\hline \multicolumn{3}{|c|}{$\mathrm{x} 10^{3}$} & & & $\mathrm{x} 10^{4}$ & & & $\mathrm{x} 10^{5}$ & \\
\hline $\mathrm{Bxx}$ & 4 & 4.5 & 4.8 & 4.2 & 0.7 & 0.98 & 1.2 & 0.19 & 0.23 \\
\hline Bxy & 0.5 & 1.0 & 1.7 & 1.6 & 0.46 & 0.79 & 1.3 & 0.26 & 0.4 \\
\hline Byx & 0.5 & 1.1 & 1.8 & 1.8 & 0.49 & 0.85 & 1.4 & 0.29 & 0.5 \\
\hline Byy & 3.5 & 4.1 & 5.6 & 9.3 & 1.2 & 2.0 & 4.4 & 1.2 & 2.23 \\
\hline
\end{tabular}

\section{CONCLUSION AND OUTLOOK}

Calculation of dynamic stiffness and damping coefficients is the background for analysis of dynamic behavior of internal gear motors and pumps. Based on the calculation results in this study, some following conclusions can be drawn 
4.1 The dynamic pressure and perturbing pressure distribution can be calculated by the use of the infinitesimal perturbation method (IFP). These pressure component is much affected by the eccentricity ratio of the ring gear center.

4.2 Dynamic oil film force is changed according to the change of eccentricity. The capacity of the oil film is mostly dependent on the vertical force element.

4.3 Dynamic stiffness and damping coefficients of the oil lubrication film is much dependent on the values of eccentricity. For large values of eccentricity, the dynamic stiffness and damping factors has high values. Among these factors, the stiffness coefficient component Kyy and damping coefficient component Byy have largest values. It will be better for stability of the ring gear at high value of eccentricity in vertical direction.

\section{ACKNOWLEDGEMENTS}

This research is funded by Vietnam National Foundation for Science and Technology Development (NAFOSTED) under grant number 107.03-2019.17.

\section{NOMENCLATURE}

$\mathrm{D}, \mathrm{r} \quad$ Diameter and radius of the ring gear $(\mathrm{m})$

Rh Radius of inner housing (m)

$\mathrm{L} \quad$ The ring gear length $(\mathrm{m})$

e Eccentricity of the ring gear center $(\mu \mathrm{m})$

c Radial clearance $(\mu \mathrm{m})$

$\varepsilon(\mathrm{e} / \mathrm{c})$ Relative eccentricity

$\varepsilon \_\mathrm{x}, \varepsilon \_\mathrm{y}$ Relative eccentricity in $\mathrm{x}$ and $\mathrm{y}$ axis

e_ $x, e \_y$ Eccentricity in axis $x, y$

$\mathrm{h} \quad$ Oil film thickness $(\mu \mathrm{m})$

K,B Stiffness and damping coefficients

$\theta \quad$ Circumferential angle from the

maximum-minimum film thickness line $\left(^{\circ}\right)$

$\mathrm{p} \quad$ Hydrodynamic film pressure $(\mathrm{Pa})$

n Rotating speed (rpm)

$\varphi \quad$ Attitude angle $\left({ }^{\circ}\right)$

$\mu \quad$ Dynamic viscosity of fluid (Pa.s)

\section{REFERENCES}

[1] B. J. Hamrock and S. R. Schmid, Fundamental of Fluid Film Lubrication Second Edition. 2004.

[2] Trong Hoa Pham, Analysis of the Ring Gear Orbit, Misalignment, and Stability Phenomenon of the Internal Gear Motors and Pumps, Shaker Verlag, 2018.

[3] Pham, T.H., Müller, L., Weber, J., Dynamically loaded the ring gear in the internal gear motor/pump: Mobility of solution, Journal of Mechanical Science and Technology, Vol. 32, No. 7, 2018.

[4] Trong Hoa Pham, Hybrid method to analysis the dynamic behavior of the ring gear for the internal gear motors and pumps, Journal of Mechanical Science and Technology, Vol. 33, No. 2, pp. 602-612, 2019.

[5] Pham Hoa, Lutz Müller, Jürgen Weber, "Theoretical and Experimental Study of Whirl and Stability Phenomenon in Internal Gear Motor/Pump", ASME/BATH FPMC Symposium on Fluid Power and Motion Control,Florida, USA, October 16-19, 2017 (doi: 10.1115/FPMC2017-4336).

[6] Trong Hoa Pham, Toan Thang Le, Wenming Cheng, Van Trung Vu, Anh Ngoc Nguyen, Thuy Chi Nguyen, "An approach to analyze the threshold stability of internal gear motors and pumps", International Conference of Fluid Machinery and Automation Systems (ICFMAS2018), pp.622-629, October 27-28, Hanoi, Vietnam

[7] S. L. Qiu., "A Theoretical and Experimental on Dynamic Characteristics of Journal Bearings", University of Wollongong, Dissertation 1995.

[8] A. . B. C. W. Stachowiak, Engineering Tribology fourth edition, vol. chapter 5. 2014. 